\title{
Recognising bereavement experiences within probation delivery
}

Natalie Rutter provides an overview of her recent research and article on the way in which people under probation supervision experience bereavement and how this can impact on desistance. 
Bereavement, loss and grief are experienced by us all, with differing responses and effects yet there has been little consideration of how individuals under probation supervision experience these issues. In this article I explore bereavement through analysis of personal stories where individual experiences of bereavement were identified as a prominent theme in my doctoral research focusing on desistance from crime and the role of relational networks (Rutter, 2021). In my research I spoke to 12 men and 13 women and adopted a longitudinal approach. This enabled the recognition of an individual's changing narratives and offered a point of reference in an ongoing story. Listening to individuals highlighted the role of emotion, trauma, attachment and the ripple effect of bereavement alongside the importance of developing and building resilience as important in the context of both bereavement and desistance.

Death occurs within a personal and social context with experiences of bereavement mirroring desistance from crime, regarded as a far from linear and straightforward process (Rutter, 2021). Life events, such as bereavement, influence desistance with relational networks playing an important role in both. Yet previous research and current practice focuses only on relationships with those still living.

\section{A process similar to desistance}

A person's experience of bereavement is unique and cannot be predicted (Doka, 2016), just like an individuals journey of desistance. Matthew highlights how his experiences of bereavement represent similarities to the zigzag nature of desistance.

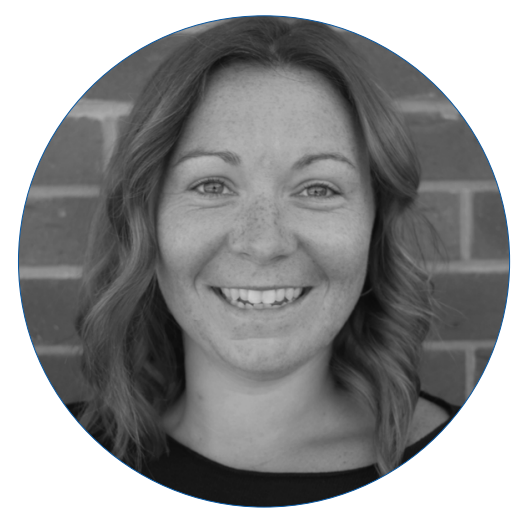

Natalie Rutter

Lecturer in Criminology and Policing, Leeds Trinity University

"it's never bothered me since he died ... it's been nearly 12 years ... a few weeks back I was sat thinking about him and I got quite upset really." (Matthew)

Here Matthew demonstrates the prolonged impact of bereavement, complicating the grieving process (Shear and Shair, 2005). During our conversations Matthew also highlighted how his emerging feelings of loss left him reconsidering his drug use as a coping mechanism which could complicate his journey of desistance through the feelings and emotions that resurfaced. 


\section{The role of emotion}

Emotionally, bereavement can be confusing and disorientating, influencing our coping mechanisms (Read and Santatzoglou, 2018) and therefore opportunities for change. Emotions are both personal and social though our interactions with others, and require consideration within experiences of both bereavement and desistance. For Jim losing his mother negatively impacted his emotional and mental health.

"The depression got worse after me mum passed away ... she didn't die of natural causes in that respect, she was married to a heroin addict." (Jim)

Jim's story also highlights the prevalence of traumatic bereavement, an experience shared by many that can pose challenges to desistance.

\section{Identifying trauma}

Alongside the circumstances surrounding death, how an individual experiences bereavement can also be traumatic. For example, suicide, murder and drug related deaths are regarded as traumatic bereavement and are often stigmatised, resulting in limited support (Perreault et al., 2010) and emotional trauma as experienced by Karen:

"When me Grandma was murdered ... I went real bad, I went pyscho. Like I was looking round for this guy ... her ex-bloke that beat her and killed her ... and I wish I never broke in ... coz there was just $f^{* *}$ king blood everywhere ... and I started getting real bad dreams." (Karen)

Unfortunately, individuals within the criminal justice system are more likely than the general population to experience traumatic bereavement (Vaswani, 2014) and loss at a disproportionate rate (De, 2018). When ignored, trauma can increase the likelihood of criminality with individuals struggling to access appropriate support (Halsey 2017), which, in turn, can hinder the process of desistance.

\section{The loss of attachment}

Sarah's story provides insight to the loss of a relationship where strong attachment is evidenced, and how - when left unresolved - can have a cumulative and continued emotional and traumatic effect:

"me girls were like you filled your life with him [father-in-law], just sitting and talking to him and then suddenly you had nothing." (Sarah)

Attachment is critical to personal development, with attachment security attained through consistent accessible and responsive experiences (Bowlby, 1982). The loss of attachment, through experiences of bereavement, can prompt sudden changes in lifestyle (Byrne and Trew, 2008) which demonstrates unpredictability and highlights the important of the ripple effect when considering the impact of bereavement.

\section{Recognising the ripple effect}

The far-reaching ripple effect of bereavement on a person's life is clear (Vaswani, 2014):

"Sometimes I wish me mum was still here because she kept us all strong and once she passed away everything just went downhill ... family feuds started." (Jim) 
Above, Matthew showed how his bereavement led to the ripples of drug addiction whilst Sarah's story highlights how her experience resulted in her involvement in gambling, ultimately leading to her engagement in criminal behaviour:

"When you look back for triggers ... when we lost me husband's dad, he died in the December and in the February, I started gambling ... my life just turned upside down nothing was normal." (Sarah)

Recognising the ripples of bereavement means taking both individual responses and wider social circumstances into account. Thus, acknowledging emotion, trauma and attachment, especially when supporting people to desist from offending becomes ever more important.

\section{Building resilience}

Building resilience is central when considering both desistance and bereavement. This was discussed by Sarah, alongside her personal responses to bereavement, gradual recovery and significant readjustment:

"I think you just have to work through it all and there is no time scale ... people deal with it differently ... I think this has been harder to get control over ... with this my life just turned upside down nothing was normal ... it did take me so long just to get me head round everything ... how it changed my life, how it changed everybody else's lives ... and I would say it's took me a good 20 months easily... to sort of get to the stage where I am now ... and maybe in like 6 months' time somebody else says something and you suddenly go whoa but I think I am in a lot better place to deal with that now." (Sarah)
Sarah's story demonstrates how her resilience developed over time as she grieved her father-inlaw and the emotion, trauma, loss of attachment and ripple effect she experienced. Importantly, all of this influenced her experiences of bereavement and desistance from crime.

\section{Practice Implications}

Recognising the unique and complex experiences of bereavement and grief, alongside the wide ranging an individual nature of impact is important for probation practice. This, in conjunction with understanding the interconnected nature of bereavement and desistance, has the potential to enable probation staff to build stronger relationships with individuals, develop understanding and offer greater support.

Concerns have been raised regarding the difficulties professionals face when attempting to engage in conversations about bereavement due to sensitivity, limited knowledge or training and insufficient awareness of resources (Read et al., 2019). In addition, a focus on risk, and its management, can result in neglecting experiences of bereavement as a welfare concern beyond the remit of those involved in rehabilitative practices (Hester and Taylor, 2011). 
To negotiate and overcome this within the context of community supervision it is important to consider the expansion, commissioning, or development of bereavement services for people under probation supervision and those working within probation (De, 2018). Engaging in conversations surrounding bereavement experiences also enables the opportunity for practice assessments (for example OASys) to be used to recognise experiences as potential dynamic risk factors. In turn, this recognises the individual and their circumstances so that the role and impact of emotion, trauma, loss of attachment and the ripple effect of bereavement are fully acknowledged.

\section{References}

Bowlby J (1982) ATTACHMENT AND LOSS: Retrospect and Prospect. American Journal of Orthopsychiatry 52(4): 664-678. https://doi. org/10.1111/j.1939-0025.1982.tb01456.x

Byrne C and K Trew (2008) Pathways Through Crime: The Development of Crime and Desistance in the Accounts of Men and Women Offenders. The Howard Journal of Criminal Justice 47(3): 238258. https://psycnet.apa.org/doi/10.1111/j.14682311.2008.00520.x

De $E$ (2018) A Literature Review into the prevalence and impact of loss and bereavement on individuals experiences severe and multiple disadvantage. London: Revolving Doors.

Doka K (2016) Grief is a journey: Finding you path through loss. New York: Atria Paperback.

Halsey M (2017) Child Victims As Adult Offenders: Foregrounding the Criminogenic Effects of
(Unresolved) Trauma and Loss. The British Journal of Criminology 58(1): 17-36. https://doi.org/10.1093/bjc/ azw097

Hester R and Taylor W (2011) Responding to bereavement, grief and loss: Charting the troubled relationship between research and practice in youth offending services. Mortality 16(3): 191-203. https:// doi.org/10.1080/13576275.2011.586121

Perreault Y, Fitton W and McGovern M (2010) The presence of absence: Bereavement in long-term survivors of multiple AIDS-related losses. Bereavement Care 29(3): 26-33. https://doi.org/10.1080/02682621 .2010 .522377

Read S and Santatzoglou S (2018) Death, Social Losses and the continuum of disenfranchised grief for prisoners. In: Read S, Santatzoglou A and Wrigley A (eds) Dying and Bereavement in the Criminal Justice System. London: Routledge: 13-21.

Read S, Santatzoglou S and Wrigley A (2019) LosS and bereavement: A guide for professionals working across the criminal justice system. London: Barrow Cadbury Trust.

Rutter, N. (2021) Negotiating bereavement and loss: influencing persistence and desistance from crime. Criminology and Criminal Justice. Online First. DOI:10.1177/17488958211016848

Shear K and Shair H (2005) Attachment, loss, and complicated grief. Developmental Psychobiology 47(3): 253-267. https://doi.org/10.1002/dev.20091

Vaswani N (2014) The Ripples of Death: Exploring the Bereavement Experiences and Mental Health of Young Men in Custody. The Howard Journal of Criminal Justice 53(4): 341-359. https://doi.org/10.1111/ hojo.12064 